\title{
14. Economic Costs and Benefits of the Proposed Basin Plan
}

\author{
R. Quentin Grafton
}

If the focus does not swing back towards considering water required for the environment, then the nation risks irretrievably damaging the attributes of the Basin that enable it to be so productive.

— Murray-Darling Basin Authority (MDBA 2010a:iv)

\section{Introduction}

This chapter examines the cost and benefits of increasing environmental flows in the Murray-Darling Basin (MDB) relative to the recent past, and the costs of business as usual of not increasing flows. The starting point for the analysis is the Guide to the proposed Basin Plan. Volume 1: Overview released on 8 October 2010 by the Murray-Darling Basin Authority (MDBA). The Guide is a consultation document that tries to give effect to the Water Act 2007 (Section 3, paragraph [d])-namely

1. to ensure the return to environmentally sustainable levels of extraction for water resources that are over-allocated or overused

2. to protect, restore and provide for the ecological values and ecosystem services of the Murray-Darling Basin. ${ }^{1}$

To achieve the objects of the Water Act 2007, the MDBA estimates that there needs to be between $3000 \mathrm{GL} / \mathrm{yr}$ and $7600 \mathrm{GL} / \mathrm{yr}$ of extra volumes of water for the environment. These volumes are specified as long-term averages such that in periods of sustained low inflows the volumes allocated to the environment would be less than average, while in periods of sustained above-normal flows the volumes allocated to the environment would be greater.

The Guide specifies a range of basin-wide volumes for the environment that are paralleled by specific environmental volumes in the principal catchments of

\footnotetext{
1 The Water Act 2007 was preceded by the National Water Initiative (NWI), which has been agreed to by all governments in the Murray-Darling Basin and the Australian Government. The NWI commits the signatories to 'complete the return of currently overallocated or overused systems to environmentally sustainable levels of extraction' (Paragraph 23, iv) and to a timetable whereby 'States and territories agree that substantial progress will be made by 2010 towards adjusting all overallocated and overused systems' (Paragraph 44).
} 
the Basin. Given that the proposed environmental volumes in most catchments within the MDB exceed current environmental flows in terms of long-term averages, there will need to be a reduction in water interceptions and/or extractions from watercourses in most parts of the Basin.

The proposed permissible water extractions for the MDB are called sustainable diversion limits (SDLs) and are specified for 19 regions. As currently proposed in the Guide, SDLs 'must reflect an environmentally sustainable level of take' (Water Act 2007, Section 23, Paragraph [1]), and, in many catchments, are less than long-term average extractions. The level of SDLs - and what should be the associated increase in volumes of water for the environment - is at the core of the debate about the proposed Basin Plan. We examine these issues in terms of the marginal benefit and the marginal cost of increased volumes of water for the environment and the costs of business as usual.

\section{Costs of Business as Usual}

Norris (2010) provides an excellent overview of the costs of business as usual. Even before the drought, the Snapshot of the Murray-Darling Basin River Condition (Norris et al. 2001) documented that 40 per cent of the river length had biota that was significantly impaired and 95 per cent had degraded environmental condition. This finding is supported by the first Sustainable Rivers Audit, released in 2008, which rated the health of 23 river valleys in the MDB. The 2008 audit found that 20 of 23 river valleys were in very poor (13) or poor (seven) health (Davies et al. 2008).

The poor state of the rivers in the MDB is a direct result of overuse that has occurred from the over-allocation of water entitlements to irrigators in decades past. The CSIRO (2008) calculates that the relative level of surface-water use in the MDB is extremely high and is likely to deteriorate, based on median climate change projections to 2030 under current water-planning arrangements, as shown in Figure 14.1. The adverse environmental effects arise not only from reduced environmental flows, but also from a change in the timing of flows. Two examples of this 'timing' problem are presented in Figure 14.2 for the Goulburn-Broken and the Murrumbidgee rivers. The green line in Figure 14.2 represents pre-development flows while the blue line represents historical flows with irrigation development. In the case of the Goulburn-Broken rivers, peak flows now occur in January-February instead of August-September. 


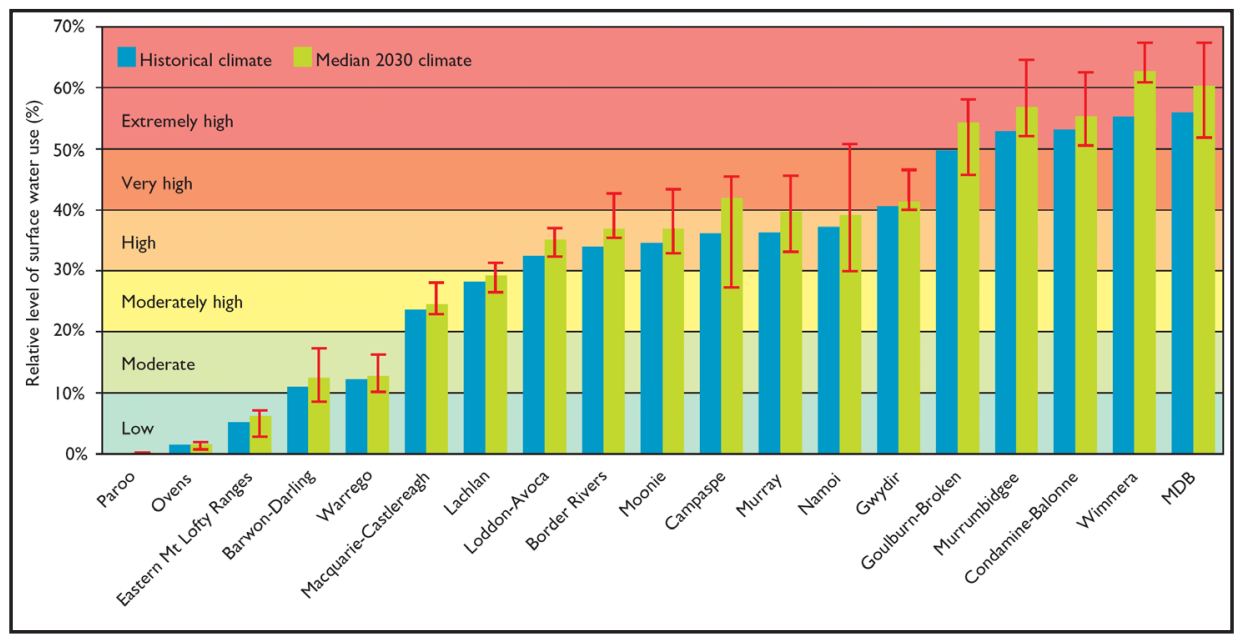

Figure 14.1 1 Relative level of water use in 18 regions and the entire Murray-Darling Basin

Source: CSIRO (2008:33).

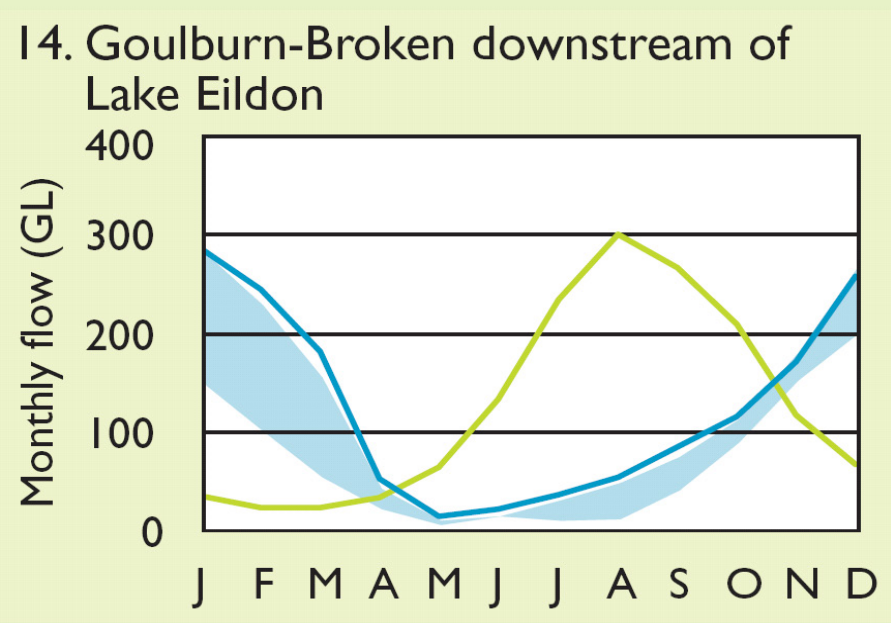

Figure 14.2a Effects of development on seasonal flows in the GoulburnBroken and the Murrumbidgee rivers

Source: CSIRO (2008:54).

On the basis of recent climate (1997-2006) and with existing water-resource plans, or business as usual, average surface-water availability in the MurrayDarling Basin would be 27 per cent less than long-term average surface-water availability. Total surface-water diversions, however, would be just 13 per cent less while total end-of-system flows would fall by about half, or about four times as much as extractions (CSIRO 2008:59). This is because 'current surface water sharing arrangements in the MDB would generally protect consumptive water users... but offer little protection for riverine environments' (CSIRO 2008:8). 


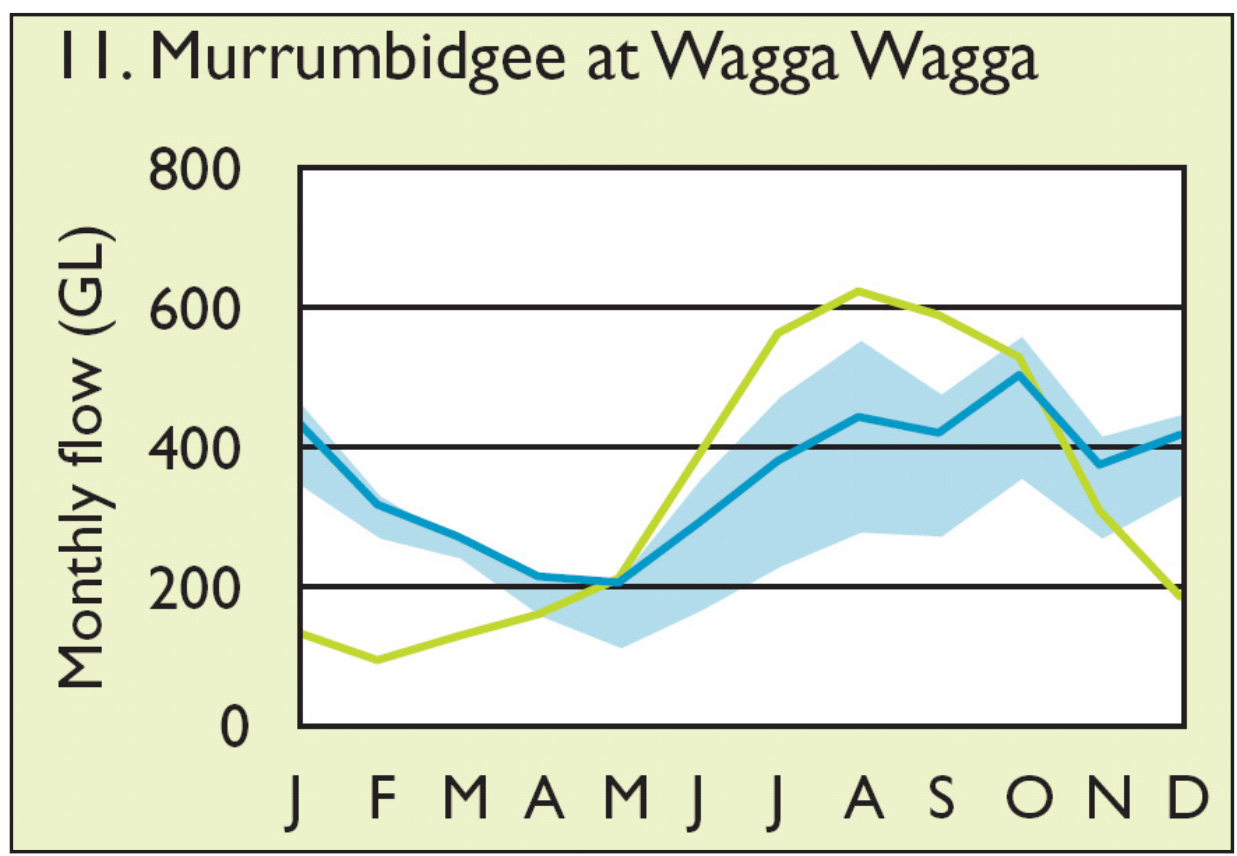

Figure 14.2b Effects of development on seasonal flows in the GoulburnBroken and the Murrumbidgee rivers

Source: CSIRO (2008:54).

These current water-planning arrangements are largely responsible for the almost zero flows at the River Murray mouth over the past decade, as shown in Figure 14.3. Prior to the development of irrigation in the Basin, zero flows at the Murray mouth were estimated to have occurred just one year in 100, on average. Using historical climate and business-as-usual water-planning arrangements, this is expected to occur 40 years every century (CSIRO 2008:5).

\section{Marginal Cost of Water Reform}

The Guide provides a summary of the possible costs to irrigated agriculture and basin employment from reductions in current diversion limits from between 3000 and 4000 GL/yr (MDBA 2010a:147) based on modelling undertaken by the Australian Bureau of Agricultural and Resource Economics-Bureau of Rural Sciences (ABARE-BRS 2010a). For the Basin as a whole, these reductions result in: 1) a lowering of forgone profits in irrigated agriculture of between 6 per cent and 9 per cent; 2) a fall in the gross value of irrigated agriculture (GVIAP) of between 13 and 17 per cent; and 3) a decline in basin employment of between 0.09 and 0.12 per cent. 


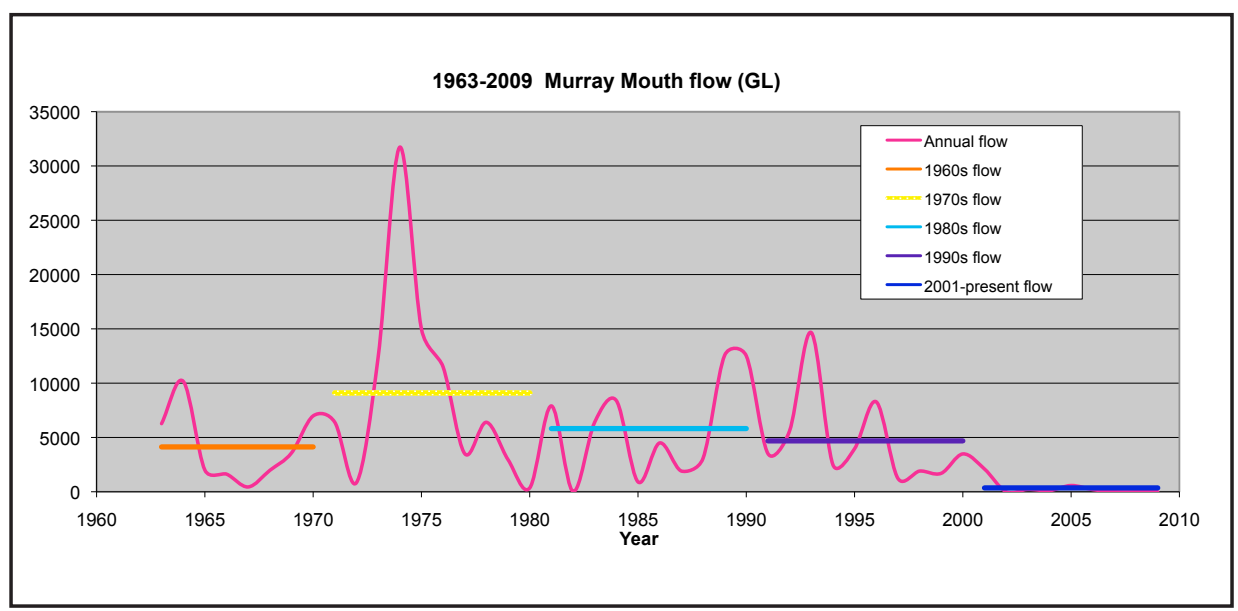

Figure 14.3 Flows at the River Murray mouth (GL/yr)

ABARE-BRS calculate the costs of reductions in current diversion limits of 3500 GL/yr under two scenarios: the implementation of the SDLs only, without offsetting government programs (Scenario 1); and with the additional funds provided to irrigators under the Water for the Future package, including the Australian Government commitment to bridge the remaining 'gap' by purchasing water entitlements from willing sellers should the desired diversion limit be less than current diversion limits (Scenario 2). Their results are obtained from a model of irrigated agriculture (Water Trade Model) that generates changes in GVIAP that links to a seven-region economic model of the MDB (AusRegion Model), as shown in Figure 14.4. Under Scenario 2, and with a 3500 GL/yr reduction in current diversion limits, the GVIAP in the Basin is predicted to fall by 10.1 per cent and profit in irrigated agriculture by 4.6 per cent. Employment in the Basin is expected to increase by 2018-19 as a result of the interventions evaluated under Scenario 2, but not with Scenario 1.

Other modelling of the effects of reductions in long-term average diversions of between 3000 and 4000 GL/yr using the Term-H20 general equilibrium model provides similar results. Namely, if irrigators are fully compensated for reduced water diversions then the impact basin wide on real gross domestic product (GDP) is small and negative, but aggregate household consumption is weakly positive (Wittwer 2010).

The ABARE-BRS and Term-H20 model results indicate only moderate impacts, basin wide, of large reductions in watercourse diversions. These findings are consistent with other models (ABARE-BRS 2010a:87-91) such as the findings of the Wentworth Group of Concerned Scientists, who predict much smaller proportional reductions in profits for a given decline in irrigated-water use. Mallawaarachchi et al. (2010:2) also find that if current cap diversion was reduced by 37 per cent then gross agricultural returns would fall by 16 per cent, and the 
loss in regional economic surplus - not accounting for the economic benefits from the sale of water entitlements - would also be 16 per cent. The small impacts basin wide, however, mask larger impacts in regions more dependent on irrigated broadacre agriculture, primarily located in the upper catchments of the Basin. For instance, ABARE-BRS (2010b:25) predict the largest absolute reductions in GVIAP will occur in the southern Basin, particularly in the Murrumbidgee, Murray (New South Wales), Murray (Victoria) and GoulburnBroken rivers regions.

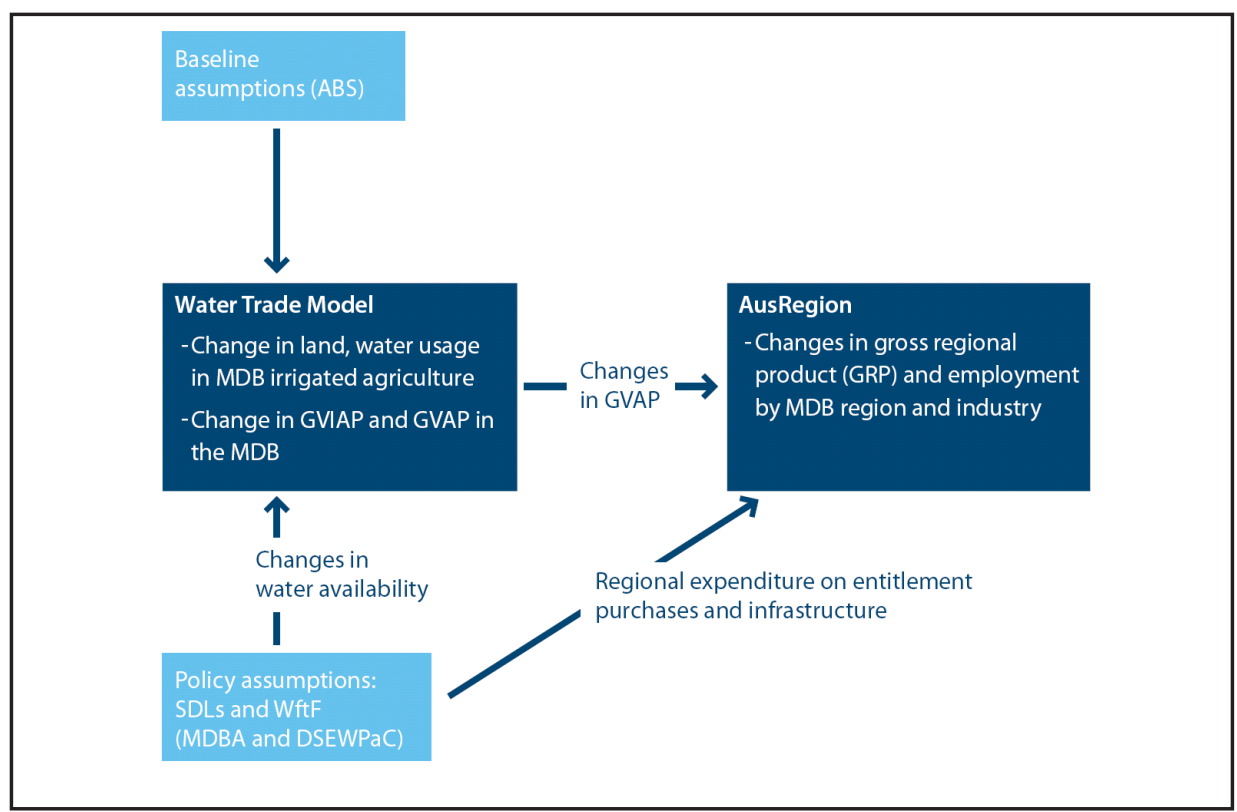

Figure 14.4 ABARE-BRS modelling of effects of reduced watercourse extractions in the Murray-Darling Basin

Source: ABARE-BRS (2010b:14).

The model results of ABARE-BRS and others (Grafton and Jiang Forthcoming; Mallawaarachchi et al. 2010) are supported by what actually happened in the recent drought. Over the period 2000-01 to 2007-08 irrigated surface-water diversions fell by about 70 per cent, yet the GVIAP in nominal terms declined by less than 1 per cent (Australian Bureau of Statistics 2010). This is because irrigators have been able to substitute other inputs (such as purchased fodder) and because water trading has reallocated water from lower to higher value irrigation uses (National Water Commission 2010:56). Indeed, some of the worst drought-affected communities (Griffith and Shepparton) actually grew in size from 2004 to 2008. While water trade has played an important role in helping to maintain GVIAP during the drought, shifts in water use due to water trade do not explain changes in population, unemployment or average incomes across regions in the Basin (National Water Commission 2010:66-7). 
In the past decade-long drought, farmers faced the twin hardship of increased water demand for their crops and uncompensated reductions in water allocations. In contrast, the August 2010 commitment by the Gillard Government to bridge the gap between current diversions and SDLs by purchasing only from willing sellers provides full compensation for any reduced allocations to water entitlements. Thus, with the transition to SDLs proposed in the Guide, farmers can plan their operations with a great deal more certainty.

A comprehensive review of the economic impacts from $\$ 1.5$ billion recovery of water entitlements by the Australian Government for the period 2008-09 to 2010-11 finds that water-entitlement sales would increase disposable incomes and consumption in regions where sales occur (Hone et al. 2010:32-3). This does not imply that there will not be negative impacts from reduced water extraction as currently proposed, but it does stress that these effects will be: 1) highly localised; 2) almost exclusively in irrigation-dependent communities primarily dependent on lower-value irrigation activities (such as irrigated broadacre agriculture); and 3) incurred by those who do not own water entitlements, but are, nevertheless, directly and indirectly dependent on irrigated agriculture for their livelihood.

\section{Marginal Benefit of Water Reform}

Some of the key benefits from increased environmental flows cannot be measured in the marketplace in terms of traded goods and services. To help overcome this information problem, economists have developed methods for non-market valuation (Champ et al. 2003). A frequently used technique is choice modelling, whereby respondents are provided with a set of choices in a questionnaire that includes environmental attributes (kilometres of healthy riverbank vegetation, frequency of bird-breeding events, and so on) and a financial cost associated with each choice. This allows the researcher to calculate a willingness to pay for marginal changes in the defined environmental attributes, which can then be aggregated to the population as a whole, based on the reported characteristics of the respondents.

Several choice-modelling exercises have been undertaken in the MDB and these are summarised by Bennett (2010). These values are site and time specific. For NSW rivers, Morrison and Bennett (2004) estimate that respondents, on average, are willing to pay between $\$ 1.25$ and $\$ 2.61$ to ensure a 1 per cent increase in the length of healthy native vegetation along their local rivers.

The most recent literature on the willingness to pay for marginal improvements in aquatic or riverine environments within the MDB is summarised by Morrison and Hatton-MacDonald (2010). They use estimates from existing studies and 
transfer these benefits to 19 regions within the Basin. The attributes they consider are in terms of water-based recreation, native vegetation, native fish, colonial water-breeding events, and for waterbirds and other species. Aggregation of the values across Australia over all attributes - except for water-based recreationyields a present value of $\$ 4.3$ billion. Thus, the present value of the willingness to pay for key environmental improvements within the MDB - and that are dependent upon environmental flows - are estimated to exceed $\$ 4$ billion.

A key challenge in using non-market estimates for environmental improvements is to relate willingness-to-pay measures for improved riverine habitats to increased environmental flows. This requires biophysical models that link increased flows or changes in timing of flows to environmental improvements. At present there are prototype models that have been developed for the Narran Lakes and Gwydir Wetlands that predict environmental outcomes in wetlands systems associated with environmental flows (Merritt et al. 2010). If these models were combined with non-market valuation studies they have the potential to provide estimates of the marginal non-market benefits of increased environmental flows.

In addition to non-market benefits, regular flooding of the Basin landscape associated with increased environmental flows provides market benefits. These include benefits in terms of water quality and improvements in soil fertility from the flushing out of salts and other contaminants from soils. There would also be substantial market benefits to floodplain graziers, who would be able to enjoy increased grazing on their properties. Estimates of the grazier benefits associated with regular flooding are some \$12.50 per hectare (Arche Consulting 2010:18).

\section{Is $3000 \mathrm{GL} / \mathrm{yr}$ Too Little?}

The MDBA has established that the minimum volume of increased flows should be, on average, $3000 \mathrm{GL} / \mathrm{yr}$ based on the best available science available as of October 2010. Engineering 'works and measures' that use pumps and infrastructure to flood key areas, and possibly adjustments in the timing of environmental flows, can be used to optimise the delivery of water for environmental purposes. There is, however, no credible evidence that such approaches justify a volume of less than $3000 \mathrm{GL} / \mathrm{yr}$ in increased environmental flows. Indeed, evidence from the management of the key-icon sites that are part of the 'Living Murray First Step' that delivers approximately $500 \mathrm{GL} / \mathrm{yr}$ to these sites suggests the converse. Namely, works and measures without much larger environmental flows are 
inadequate because 'the inability to direct large volumes of water to sites over the past 5 years... raises real concerns about the ability to maintain or improve the condition of each site' (Swirepik 2009:3).

There is supporting evidence from previous studies that indicates that, for the Murray River alone, an additional $3350 \mathrm{GL} / \mathrm{yr}$ in environmental flows, along with improved river operations, would be required to ensure a high probability of a healthy, working Murray River. The Wentworth Group of Concerned Scientists et al. (2010) have estimated that the Basin as a whole would need an additional $4400 \mathrm{GL} / \mathrm{yr}$ to avoid a substantial risk that the rivers of the Basin will fail to be in a healthy state. A similar methodology used by the Wentworth Group of Concerned Scientists has also been adopted by the MDBA in defining a target range for desired environmental flows. The MDBA (2010b:108-10) specifies that to ensure key ecosystem functions, environmental flows should be at least 60 per cent of without-development flows. Such volumes, however, would ensure only a high degree of uncertainty to achieve desired environmental goals. An environmental flow regime of 80 per cent of without-development flows would give a low degree of uncertainty to achieve desired environmental goals.

The $3000 \mathrm{GL} / \mathrm{yr}$ increase in environmental flows recommended as a minimum by the MDBA (2010a) represents an even greater degree of uncertainty than the case of 60 per cent of without-development flows. The $3000 \mathrm{GL} / \mathrm{yr}$ target is also predicted to leave the Condamine-Balonne, Gwydir, Loddon, Lower Darling and the Murray regions of the Basin (MDBA 2010a:74) in 'poor' status. The reason $3000 \mathrm{GL} / \mathrm{yr}$ falls outside the MDBA's own target level is because the high uncertainty target for end-of-system flows is actually $3856 \mathrm{GL} / \mathrm{yr}$. Thus, using the MDBA's own confidence intervals of $+/-20$ per cent, the lowest boundary of the confidence interval for a high degree of uncertainty consistent with environmental flows at 60 per cent of without-development flows is $3085 \mathrm{GL} / \mathrm{yr}$ (MDBA 2010b:114-15). In contrast, the upper-end confidence limit with a high degree of uncertainty is $4615 \mathrm{GL} / \mathrm{yr}$.

\section{Is 4000 GL/yr Too Much?}

The MDBA has advised that the maximum desired increase in environmental flows should be no more than $4000 \mathrm{GL} / \mathrm{yr}$ based on social and economic information. This upper limit of $4000 \mathrm{GL} / \mathrm{yr}$ is an attempt by the MDBA to balance the need for increased water in the landscape against the costs to irrigated agriculture and irrigation-dependent communities of reduced water interceptions and/or watercourse extractions. This is because the Water Act 2007 obliges the MDBA to prepare a plan such that 'the economic, social and environmental outcomes are optimised and the net economic returns are maximised'. The socioeconomic 
considerations, however, are subsidiary to the objects of the Water Act 2007, which are to ensure levels of extraction 'will not compromise the environmental water requirements of key environmental assets including water-dependent ecosystems; ecosystem services and sites of ecological significance; [and] key ecosystem functions'.

The subsidiarity of socio-economic considerations to meeting the environmental objectives of the Water Act 2007 is emphasised by legal expert Professor George Williams of the University of New South Wales, who observes that these environmental considerations take precedence and that local economic and other concerns must be taken into account "subject to them"" (Williams 2010). Thus, limiting the maximum increase in environmental flows to $4000 \mathrm{GL} / \mathrm{yr}$ can be justified only if there is sufficient certainty that such volumes will achieve the environmental goals of the Water Act 2007.

Ideally, the desired increase in environmental flows from a societal perspective should be a volume of water that generates environmental outcomes such that the marginal benefit in dollars of an extra gigalitre per year of water for the environment equals the marginal cost in dollars from reduced interceptions or extractions to generate these increased flows. A stylised representation of this outcome is provided in Figure 14.5, where it is supposed that the marginal benefit of additional environmental flows declines with the cumulative amount allocated to the environment.

A possible justification for a downward-sloping marginal benefit curve is that at very low volumes of water allocated to the environment widespread die-offs would be expected in vegetation and species, as well as major problems in water quality, such as from algal blooms and acidity from the prolonged exposure of acid-sulphate soils. If the landscape were to receive successively greater volumes of water, the extra benefits of environmental watering would still remain positive, but would eventually diminish as the minimum volumes needed to avoid crossing minimum critical thresholds were achieved.

In contrast, the marginal cost of reduced interceptions or extractions increases with the amount of environmental flows. The justification for a rising marginal cost is that reductions in extractions can, initially, be achieved at a relatively low cost because there are uses of water for irrigated agriculture that generate low net returns. As more and more water is allocated to the environment, however, progressively more profitable forms of irrigation would have to get by with less water and, thus, the extra costs of reduced extractions would increase. 


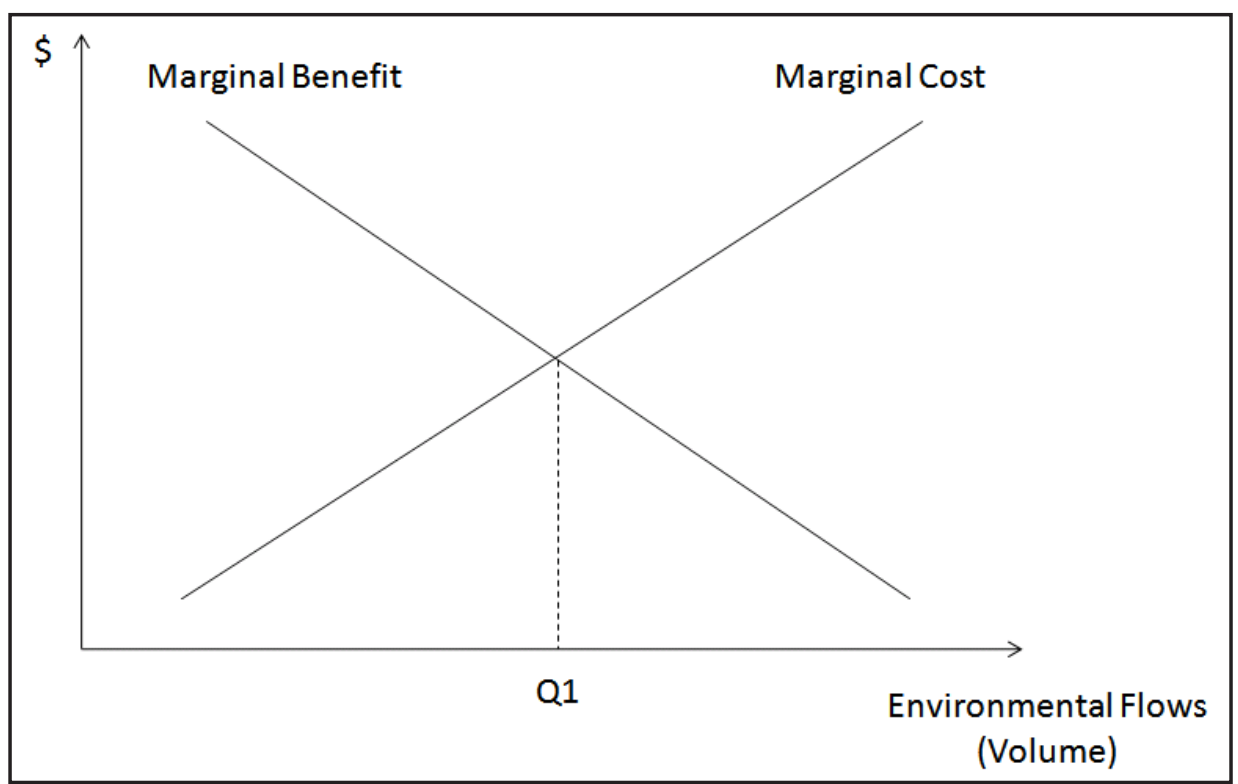

\section{Figure 14.5 Marginal benefits equals marginal costs}

Figure 14.5 represents the marginal benefit and marginal cost curves as straight lines that are 'smooth' with no breaks, flat areas or kinks. In reality, we might expect the marginal benefit curve to be steeper, and possibly discontinuous, at low volumes to indicate threshold points beyond which there might be very large losses associated with low environmental flows. Similarly, we might expect marginal cost to rise more steeply as the volumes of water in the environment increase to reflect the fact that higher-value extractive uses might be worth much more than low-value irrigation uses.

The volume of water for the environment that maximises societal benefits is represented by Q1 in Figure 14.5. Volumes of water to the environment less than Q1 generate a result that the marginal benefit from environmental flows is greater than the marginal cost of reduced interceptions or extractions. Thus, society, as a whole, would be better off by increasing environmental flows. Volumes of water greater than Q1 result in the marginal cost of environmental flows that exceeds the marginal benefit of such flows, from a societal perspective. Consequently, society as a whole would be better off if there were to be lower environmental flows. The desired volume of environmental flows from a societal perspective is, thus, achieved at Q1 where the marginal benefit equals the marginal cost.

At present there is insufficient information to precisely determine the desired increase in environmental volumes such that the marginal benefit of greater environmental flows equals the marginal cost of reduced extractions. There is, however, modelling calibrated to the Murray River that assesses the tradeoffs between the environment and surface-water extractions by irrigators that 
indicates environmental flows should have been much larger over the past decade (Grafton et al. forthcoming). Equally as important, there is also no credible economic evidence to justify the assertion by the MDBA that $4000 \mathrm{GL} /$ yr imposes unacceptably high socioeconomic costs. Indeed, there is evidence that implies the opposite - namely: 1) if large increases in environmental flows are consistent with improvements in environmental assets then increased flows have the potential to deliver multiple billions of dollars of non-market benefits in present value terms, and in excess of $\$ 1$ billion per year; 2 ) the annual estimated willingness to pay for improvements in riverine environmental assets in the $\mathrm{MDB}^{2}$ exceeds the estimated annual reduction in the gross regional product in the Basin associated with a $4000 \mathrm{GL} / \mathrm{yr}$ reduction in watercourse diversions, while having virtually no impact on the long-term employment within the Basin (MDBA 2010a:121); 3) reductions in current watercourse diversions to holders of water entitlements will be fully compensated by the $\$ 3.1$ billion allocated to the purchase of water entitlements in the Water for the Future package, and by the commitment of the Australian Government to acquire water entitlements only from willing sellers; 4) according to the MDBA's own evidence and its own confidence intervals, a decrease in diversions basin wide of less than $4615 \mathrm{GL} / \mathrm{yr}$ would still achieve only key ecosystem functions consistent with a high degree of uncertainty (MDBA 2010b:112).

\section{Mitigating the Costs of Water Reform}

To mitigate the costs of water reform, the MDBA has opted to limit the proposed increase in environmental flows. A downside to this approach is that if the proposed environmental flows fail to meet the objects of the Water Act 2007, the SDLs on which the Basin Plan is based become vulnerable to litigation. Moreover, the smaller the increase in proposed environmental flows the greater is the risk of incurring at least some of the costs of business as usual.

While it might be possible in the future to achieve the same environmental objectives with less water, or with better timing of water releases, there is at present no credible scientific evidence to support basin-wide reductions in proposed environmental flows on the basis of past 'works and measures'. This is because '[m]ajor wetlands require large-scale inundation events, managed or not' (Kingsford et al. 2010:29). It is possible that, given sufficient time, coupled with appropriate incentives at the site or catchment scale for water environmental managers, and by learning by doing, there will be improved ways to provide water for the environment. If this were to be the case then this would be accounted for in the determination of SDLs in any subsequent Basin Plan.

2 This depends on the discount rate used to generate the present value numbers. 
An alternative way to reduce the socioeconomic impacts of lowering current water diversions is to provide adjustment or transitional assistance to irrigationdependent communities expected to suffer the most from the proposed changes. This addresses the issue that '[a]ny fall-off of economic activity as a result of the Basin Plan will also be felt by those in the irrigated agriculture chain. These people are typically "outside the tent" when it comes to compensation; they need to be included in community adjustment planning' (Marsden Jacob Associates et al. 2010:xxi-xxii).

According to ABARE-BRS, the people most affected and who are currently 'outside the tent' in terms of compensation are individuals who do not own water entitlements and are located in irrigation communities in the Murrumbidgee, Condamine, Murray (New South Wales and Victoria), Gwydir, Barwon-Darling and Goulburn-Broken river regions of the MDB. The Wentworth Group of Concerned Scientists et al. (2010) have proposed a 'reasonable return and community development' option that would provide transitional assistance to affected communities to cope with less water for extraction. Under this approach, the amount of funding available to communities would be predicated on the expected and/or actual economic impacts of reduced water diversions. Communities themselves, with external assistance and advice, would develop proposals for funding and other support and these would be tested for 'value for money' in terms of an expected rate of return. Funds for transitional assistance could come from the Water for the Future program, especially if some of the $\$ 5.8$ billion currently directed for irrigation infrastructure subsidies in Water for the Future were redirected to buying water entitlements from willing sellers and supporting community adjustment (Grafton 2010).

An approach to structural adjustment proposed by the Wentworth Group of Concerned Scientists is to engage communities in the 'thriving communities' model. This approach includes three steps: 1) facilitation and bringing together of people and leaders in the community; 2) development of plans and ideas for co-investment; and 3) funding and follow through on the initiatives (Miller and Verity 2009). A necessary but not sufficient condition for success, as evidenced by successful adjustment in other resource sectors, is ' $t \mathrm{t}]$ he absolute necessity for some individuals to be willing to take a leadership role-requiring at times considerable personal courage and a commitment to change-across the interests of all the stakeholder groups in order to progress the necessary change management' (McLoughlin and Rayns 2010:344).

The adjustment process in Australia's Commonwealth fisheries shows that it is possible to undertake structural adjustment and generate better societal outcomes. In this process, the Australian Government spent $\$ 220$ million in 2006-07 to buy back fishing licences, to provide onshore business assistance, to give three years of relief from government industry levies, and to provide 
additional funds for scientific research (McLoughlin and Rayns 2010:341). The outcomes of these industry adjustments, along with management rules that enforce reduced harvests when required, have helped to generate higher net returns for harvesters and increased the asset values of the harvesting rights of fishers. In addition, following these changes, between 2006 and 2009, the proportion of fish stocks classified as overfished and uncertain in their stock status fell from 72 per cent to less than half, while the number of species not overfished has more than doubled (Wilson et al. 2010:19).

\section{Concluding Remarks}

The Guide to the proposed Basin Plan offers a major step forward in water planning in Australia, and worldwide. It performs the difficult task of reconciling the trade-offs between allocating more water for the environment versus water for existing users while complying with the Water Act 2007. According to the Murray-Darling Basin Authority, the best available science indicates that the Murray-Darling Basin needs a great deal more water-between 3000 GL/yr and $7600 \mathrm{GL} / \mathrm{yr}$ - to meet desired ecosystem functions and the objects of the Act. Using the MDBA's own technical documentation and its own confidence intervals, any reductions in diversions of less than $4615 \mathrm{GL} / \mathrm{yr}$ would, however, only achieve the goals of the Water Act 2007 with a high degree of uncertainty.

A review of the results of socioeconomic models of the Basin, and also empirical evidence over the past decade-long drought, provides no support for the recommendation by the MDBA that increases in environmental flows should be limited to $4000 \mathrm{GL} / \mathrm{yr}$ due to the high socioeconomic impacts of reduced water diversions. Instead, a more effective approach to minimise the socioeconomic impacts of increased environmental flows is to provide transitional assistance to irrigation-dependent communities to help them adjust to a future with lower water extractions. This would require a redirection of existing funding for water reform and/or the allocation of additional funds expressly for this purpose.

\section{Bibliography}

Arche Consulting 2010, Socioeconomics of floodplain agriculture in the MurrayDarling Basin: a scoping report, Mimeograph, Arche Consulting, Sydney.

Australian Bureau of Agricultural and Resource Economics (ABARE) and Bureau of Rural Sciences (BRS) 2010a, Environmentally sustainable diversion limits in the Murray-Darling Basin: socioeconomic analysis, Report prepared for the Murray-Darling Basin Authority, Canberra. 
Australian Bureau of Agricultural and Resource Economics (ABARE) and Bureau of Rural Sciences (BRS) 2010b, Assessing the regional impact of the MurrayDarling Basin Plan and the Australian Government's Water for the Future Program in the Murray-Darling Basin, Report prepared for the MurrayDarling Basin Authority, Canberra.

Australian Bureau of Statistics 2010, Experimental Estimates of the Gross Value of Irrigated Agricultural Production, 2000-0102007-08, Australian Bureau of Statistics, Canberra.

Bennett, J. 2010, 'Making decisions about environmental water: an economics approach', in Making decisions about environmental water allocations, Research Report, Australian Farm Institute, Surry Hills, NSW.

Champ, P. A., Boyle, K. J. and Brown, T. C. (eds) 2003, A Primer on Nonmarket Valuation, Kluwer Academic Press, Dordrecht.

CSIRO 2008, Water availability in the Murray-Darling Basin, A report to the Australian Government from the CSIRO Murray-Darling Basin Sustainable Yields Project, Canberra.

Davies, P. E., Harris, J. H., Hillman, T. J. and Walker, K. F. 2008, A report on the ecological health of rivers in the Murray-Darling Basin 2004-2007, Report by the Independent Sustainable Rivers Audit Group for the Murray-Darling Commission, Canberra.

Grafton, R. Q. 2010, 'How to increase the cost effectiveness of water reform and environmental flows in the Murray-Darling Basin', Agenda, vol. 17, no. 2, pp. 17-40.

Grafton, R. Q. and Jiang, Q. (Forthcoming), Economic effects of water recovery on irrigated agriculture in the Murray-Darling Basin, Paper. Australian Journal of Agricultural and Resource Economics.

Grafton, R. Q., Chu, L., Stewardson, M. and Kompas, T. (Forthcoming), 'Optimal dynamic water allocation: irrigation extractions and environmental tradeoffs in the Murray River, Australia', Water Resources Research.

Hone, S., Foster, A., Hafi, A., Goesch, T., Sanders, O., Mackinnon, D. and Dyak, B. 2010, Assessing the future impact of the Australian Government environmental water purchase program, ABARE Research Report 10.03, Australian Bureau of Agricultural and Resource Economics, Canberra.

Jones, G., Hillman, T., Kingsford, R., McMahon, T., Walker, K., Arthington, A., Whittington, J. and Cartwright, S. 2002, Independent Report of the Expert 
Reference Panel on Environmental Flows and Water Quality Requirements for the River Murray System, Prepared for the Environmental Flows and Water Quality Objectives for the River Murray Project Board, Canberra.

Kingsford, R. T., Brandis, K. J., Jenkins, K. M., Nairn, L. C. and Rayner, T. S. 2010, 'Measuring ecosystem responses to flow across temporal and spatial scales', in N. Saintilan and I. Overton (eds), Ecosystem Response Modelling in the Murray-Darling Basin, CSIRO Publishing, Collingwood, Vic.

McLoughlin, R. and Rayns, N. 2010, 'Australia's Commonwealth-managed fisheries', in R. Q. Grafton, R. Hilborn, D. Squires, M. Tait and M. Williams (eds), Handbook of Marine Fisheries Conservation and Management, Oxford University Press, New York.

Mallawaarachchi, T., Adamson, D., Chambers, S. and Schrobback, P. 2010, Economic Analysis of Diversion Options for the Murray-Darling Basin Plan: Returns to irrigation under reduced water availability, Risk and Sustainable Management Group, University of Queensland, St Lucia.

Marsden Jacob Associates, RMCG, EBC Consultants, DBM Consultants, The Australian National University, McLeod, G. and Cummins, T. 2010, Synthesis report: economic and social profiles and impact assessments in the MurrayDarling Basin, A report to the Murray-Darling Basin Authority, Canberra.

Merritt, W., Powell, S., Pollino, C. and Jakeman, T. 2010, 'IBIS: a decision support system for managers of environmental flows into wetlands', in $\mathrm{N}$. Saintilan and I. Overton (eds), Ecosystem Response Modelling in the MurrayDarling Basin, CSIRO Publishing, Collingwood, Vic.

Miller, C. and Verity, F. 2009, Thriving communities: addressing and adjusting to the social impacts of water related changes in the Murray-Darling Basin, Mimeograph, Flinders University, Adelaide.

Morrison, M. and Bennett, J. 2004, 'Valuing New South Wales rivers for use in benefit transfer', Australian Journal of Agricultural and Resource Economics, vol. 48, no. 4, pp. 591-611.

Morrison, M. and Hatton-MacDonald, D. 2010, Economic Valuation of Environmental Benefits in the Murray-Darling Basin, Murray-Darling Basin Authority, Canberra, <http://www.mdba.gov.au/files/bp-kid/1282-MDBANMV-Report-Morrison-and-Hatton-MacDonald-20Sep2010.pdf $>$

Murray-Darling Basin Authority (MDBA) 2010a, Guide to the proposed Basin Plan. Volume 1: Overview, Murray-Darling Basin Authority, Canberra. 
Murray-Darling Basin Authority (MDBA) 2010b, Guide to the proposed Basin Plan. Volume 2: Technical background, Murray-Darling Basin Authority, Canberra.

National Water Commission 2010, The Impacts of Water Trading in the Southern Murray-Darling Basin: An economic, social and environmental assessment, National Water Commission, Canberra.

Norris, R. H. 2010, 'How should Australia decide how much water in Australian rivers should be allocated to the environment, and how can the community be sure environmental water is being used efficiently?', Making decisions about environmental water allocations, Research Report, Australian Farm Institute, Surry Hills, NSW.

Norris, R. H., Liston, P., Davies, N., Dyer, F., Coysh, J., Dyer, F., Linke, S., Prosser, I. and Young, B. 2001, Snapshot of the Murray-Darling Basin River Condition, Murray-Darling Basin Commission, Canberra.

Swirepik, J. L. 2009, Establishing and delivering environmental water allocations in the Murray River, Australia, Paper presented at the International Conference on Implementing Environmental Water Allocations, 23-26 February 2009.

Wentworth Group of Concerned Scientists in association with Grafton, R. Q., Kowalick, I., Miller, C., Stubbs, T., Verity, F. and Walker, K. 2010, Sustainable Diversions in the Murray-Darling Basin: An analysis of the options for achieving a sustainable diversion limit in the Murray-Darling Basin, Wentworth Group of Concerned Scientists, Sydney, <http://www.wentworthgroup.org/ uploads/Sustainable \%20Diversions \%20in \%20the \% 20Murray-Darling \% 20 Basin.pdf>

Williams, G. 2010, 'When water pours into legal minefields', Sydney Morning Herald, 26 October 2010, <http://www.smh.com.au/opinion/politics/whenwater-pours-into-legal-minefields-20101025-170uf.html>

Wilson, D., Curtotti, R. and Vieira, S. 2010, 'Overview', in D. T. Wilson, R. Curtotti and G. A. Begg (eds), Fishery Status Reports 2009: Status of fish stocks and fisheries managed by the Australian Government, Bureau of Rural Sciences, Australian Bureau of Agricultural and Resource Economics, Canberra.

Wittwer, G. 2010, The regional economic impacts of sustainable diversion limits, 5 November 2010, Report prepared for the Murray-Darling Basin Authority, Canberra. 